\title{
Life as a bachelor: quantifying the success of an alternative reproductive tactic in male blue monkeys
}

Su-Jen Roberts, Marina Cords

In species that live in one-male groups, resident males monopolize access to a group of females and are assumed to have higher reproductive success than bachelors. We tested this assumption using genetic, demographic, and behavioral data from 8 groups of wild blue monkeys observed over 10 years to quantify reproduction by residents and bachelors and compare the success of the two tactics. We used maximum-likelihood methods to assign sires to 104 offspring born in the study groups, 36 of which were sired by extragroup males, i.e., residents of neighboring groups and bachelors. Among these extra-group males, high-ranking males (many of whom were neighboring residents) were more likely to sire offspring than low-ranking males, but the time these visiting males spent in the mother's group when she conceived (male presence) did not predict their relative success. When bachelors competed for reproduction with other bachelors, neither rank nor male presence during the mother's conceptive period affected the probability of siring an offspring, suggesting that highly opportunistic mating with conceptive females is important in bachelor reproduction. In a second analysis, we used long-term data to estimate resident and bachelor reproductive success over the long term, and particularly to determine if there are any circumstances in which a typical bachelor may sire as many offspring as a typical resident during one or two periods of residency. Our findings generally support the assumption of a resident reproductive advantage because in most circumstances, a lifelong bachelor would be unable to sire as many offspring as a resident. However, a bachelor who performs at the average rate in the average number of groups for several years may have similar lifetime reproductive success as a male whose reproduction is limited to one short period of residency, especially in a small group. Our findings suggest that one should not assume a resident reproductive advantage for males in one-male groups in all circumstances. 
1 TiTLE: Life as a Bachelor: Quantifying the Success of an Alternative Reproductive Tactic

2 in Male Blue Monkeys

3

4 Authors: Su-Jen Roberts ${ }^{\mathrm{abc}}$ and Marina Cords ${ }^{\mathrm{ab}}$

5 a Department of Ecology, Evolution, and Environmental Biology, Columbia University,

6 New York, NY, USA

7 bew York Consortium in Evolutionary Primatology, New York, NY, USA

$8 \quad{ }^{\mathrm{c}}$ New Knowledge Organization Ltd., New York, NY, USA

9

10 CORRESPONDING AUtHOR: Su-Jen Roberts

11 New Knowledge Organization, 13 E. $37^{\text {th }}$ Street, $7^{\text {th }}$ Floor, New York, NY 10016, USA

12 Phone: $814-441-5260$

13 Email: sroberts@newknowledge.org 


\section{ABSTRACT}

15 In species that live in one-male groups, resident males monopolize access to a group of

16 females and are assumed to have higher reproductive success than bachelors. We tested

17 this assumption using genetic, demographic, and behavioral data from 8 groups of wild

18 blue monkeys observed over 10 years to quantify reproduction by residents and bachelors

19 and compare the success of the two tactics. We used maximum-likelihood methods to

20 assign sires to 104 offspring born in the study groups, 36 of which were sired by extra-

21 group males, i.e., residents of neighboring groups and bachelors. Among these extra-

22 group males, high-ranking males (many of whom were neighboring residents) were more

23 likely to sire offspring than low-ranking males, but the time these visiting males spent in

24 the mother's group when she conceived (male presence) did not predict their relative

25 success. When bachelors competed for reproduction with other bachelors, neither rank

26 nor male presence during the mother's conceptive period affected the probability of siring

27 an offspring, suggesting that highly opportunistic mating with conceptive females is

28 important in bachelor reproduction. In a second analysis, we used long-term data to

29 estimate resident and bachelor reproductive success over the long term, and particularly

30 to determine if there are any circumstances in which a typical bachelor may sire as many

31 offspring as a typical resident during one or two periods of residency. Our findings

32 generally support the assumption of a resident reproductive advantage because in most

33 circumstances, a lifelong bachelor would be unable to sire as many offspring as a

34 resident. However, a bachelor who performs at the average rate in the average number of

35 groups for several years may have similar lifetime reproductive success as a male whose

36 reproduction is limited to one short period of residency, especially in a small group. Our 
37 findings suggest that one should not assume a resident reproductive advantage for males

38 in one-male groups in all circumstances. 
40 In species with strong male-male competition for females, individual males often

41 adopt alternative reproductive tactics to maximize reproductive output within the

42 constraints of social, demographic, and ecological conditions (Gross 1996; Neff \&

43 Svensson 2013). In male mammals, alternative reproductive tactics usually have unequal

44 fitness payoffs; the most competitive males use the tactic with the highest payoff, while

45 less competitive males use surreptitious behavior to gain access to females, resulting in

46 lower reproductive success (Wolff 2008; Taborsky \& Brockmann 2010). Individuals

47 may, however, switch tactics over the course of a lifetime or even during a single

48 breeding season, in response to factors like their relative competitive ability and the

49 proportion of males pursuing each tactic (Repka \& Gross 1995; Taborsky \& Brockmann

50 2010).

51 Many mammals live in one-male/multi-female groups, a type of social

52 organization in which one resident male is consistently associated with a group of

53 females while bachelor males live alone or form bachelor groups. Males compete for the

54 resident position (e.g., Le Boeuf 1974; Clutton-Brock 1982), suggesting that the resident

55 tactic of defending access to a group of females results in higher fitness than the bachelor

56 tactic of stealing matings. Paternity studies from several mammals living in one-male

57 groups strongly support this prediction, in that residents sired all offspring born in their

58 groups (Schwartz \& Armitage 1980; Pope 1990; Launhardt et al. 2001), which suggests

59 that lifelong bachelors do not sire any offspring. In other mammals, however, residents

60 lost some paternity to outsiders, including bachelors and residents of adjacent groups

61 (Pemberton et al. 1992; Asa 1999; Hoelzel et al. 1999; Storz, Bhat \& Kunz 2001; Heckel 
62 \& Von Helversen 2003; Fabiani et al. 2004; Feh \& Munkhtuya 2008; Hirsch \&

63 Maldonado 2011; Roberts, Nikitopoulos \& Cords 2014). While an alternative

64 reproductive tactic may exist in these species, the success of individual bachelors and the

65 factors affecting whether they sire offspring are not well understood. Furthermore, few

66 studies have directly compared the success of bachelor and resident tactics in long-lived

67 mammals (but see: Sommer \& Rajpurohit 1989; MacLeod, Ross \& Lawes 2002) because

68 it is difficult to follow males over their entire reproductive lives. Quantifying the success

69 of alternative tactics and identifying the conditions under which each does best allows us

70 to better understand the role of male-male competition in determining the evolution of

71 social organization.

72 We studied male reproductive tactics in blue monkeys (Cercopithecus mitis), a

73 guenon that lives typically in one-male groups. Even as a long-term resident, male blue

74 monkeys regularly face competition from extra-group males, who may be bachelors,

75 unattached to any group, or residents in adjacent groups (n.b., there are no all-male

76 groups). These extra-group males compete with a resident by spending time in his group

77 during the mating season, and copulating with his females (Cords 2000). Neighboring

78 residents are especially likely to steal copulations during aggressive intergroup

79 encounters (which involve primarily the females; Cords 2007). In addition, about $25 \%$ of

80 mating seasons in our study population are characterized by particularly strong male-

81 male competition when multiple extra-group males temporarily join the group for various

82 periods (from days to months), leaving when the mating season ends (Cords 2002). These

83 multi-male influxes are especially likely when multiple females are simultaneously

84 sexually active (Cords 2002; Mugatha et al. 2007) and they reduce the probability that a 
85 resident male sires offspring conceived in his group (Roberts, Nikitopoulos \& Cords

86 2014). These findings suggest that stealing matings may be a profitable bachelor tactic

87 (Rowell \& Chism 1986).

88 Individual bachelors in the study population typically sire fewer offspring than

89 residents within a single group-year (Roberts et al. 2014), but there is variation in

90 bachelor success, and its causes are as yet unexplored. In addition, little is known about

91 how resident or bachelor tactics translate into lifetime reproductive success. Comparing

92 resident and bachelor reproductive success would help determine if the high costs

93 associated with residency allow bachelors to make up some of the difference in

94 reproduction by pursuing the lower-cost, lower-gain tactic for an extended period

95 (Widemo 1998; MacLeod, Ross \& Lawes 2002). In this study, we used molecular,

96 demographic, and behavioral data collected from 8 social groups of wild blue monkeys

97 over 10 years to assess the absolute and relative success of the bachelor tactic. We

98 present our methods and results in two parts to increase clarity: Part I focuses on the

99 factors that drive differential siring success among extra-group males, while Part II

100 compares the lifetime reproductive success of bachelors vs. residents.

101 Part I: Factors AfFecting Extra-Group Male Siring Success

102 PART I METHODS

103 Ethical Note

104 This research adhered to the ABS guidelines for the treatment of animals in

105 behavioral research. Methods were approved by the Columbia University IACUC (\# AC-

106 AAAD9003), the National Council for Science and Technology, the Kenya Wildlife

107 Service and National Environmental Management Authority. 


\section{Study Site and Population}

109 The study population of blue monkeys in the Kakamega Forest, Kenya (Mitchell,

110 Schaab \& Wagele 2009) has been monitored since 1979 (Cords 2012). Our study focused

111 on the period between 2002 and 2011, during which 3 group fissions increased the

112 number of simultaneously existing study groups from 3 to 6 . We used data from a total of

1138 unique groups, each present for 1-10 years during the study period. Authors and field

114 assistants observed groups on a near daily basis to record demographic information

115 including infant birthdates, presence of sexually active females and of extra-group males

116 (both neighboring residents and bachelors) in or on the edge of the group, and dates of

117 resident male turnover. They also recorded all observed agonistic interactions among

118 males, noting participant identity and outcome.

119 Genetic Data

120 We used fecal samples from 126 infants, 64 mothers, and 60 adult males,

121 including 11 resident males in our study groups, for genetic analysis. We collected

122 samples shortly after defecation, storing them in sterile tubes mixed with RNALater ${ }^{\mathrm{TM}}$

123 (Ambion) to preserve the DNA.

124 Extraction and genotyping methods are described in Roberts et al. (2014). Briefly, 125 we extracted DNA from fecal samples using the QIAamp ${ }^{\circledR}$ DNA Stool Mini Kit 126 (Qiagen) and amplified it at 13 human MapPairs ${ }^{\circledR}$ microsatellite markers (Invitrogen).

127 We used the ABI 3730 Automated DNA Analysis system and GeneMapper 3.7 (Applied 128 Biosystems) for genotyping.

129 We conducted likelihood-based paternity analysis with CERvUs 3.0 (Kalinowski,

130 Taper \& Marshall 2007), using simulation parameters noted in Roberts et al. (2014). 
131 CERVUS assigned paternity to 108 offspring with $80 \%$ or $95 \%$ confidence (for details, see

132 Roberts et al. 2014). We further verified assignments by examining the number of

133 mismatches between the offspring and assigned sire, excluding mismatches for which

134 both individuals were homozygous because they may have resulted from allelic dropout.

135 Mother-offspring pairs mismatched rarely and never at more than 1 locus. Similarly, 104

136 of the 108 offspring-assigned sire pairs mismatched at 0 or 1 locus and we considered

137 these assignments to be robust. The remaining 4 offspring mismatched their assigned sire

138 at 2 loci, so we omitted them from the final analysis.

139 Behavioral Data

140 We used demographic data to identify factors affecting the siring success of extra-

141 group males. We were interested in how extra-group males compete among themselves

142 for reproductive opportunities so considered only the offspring sired by bachelors or

143 residents of adjacent groups (i.e., neighboring residents). Specifically, we tested how

144 male presence and dominance rank affected the probability of siring an offspring.

145 Blue monkey females do not signal fertile periods with morphological changes

146 such as sexual swellings, so we identified the period in which an infant's conception

147 occurred (conceptive period) using a combination of demographic records and behavioral

148 observations. First we identified a 29-day conception window for each offspring by

149 subtracting the length of one gestation (176 \pm 14 days, the $95 \%$ confidence interval, Pazol,

150 Carlson \& Ziegler 2002) from offspring birthdates, which were accurate to 1-3 days.

151 Within this window, we then identified the conceptive period based on female sexual

152 behavior (copulations and proceptive behavior), following Pazol (2003) and Roberts et al.

153 (2014). We identified conceptive periods for the mothers of 28 of the 36 offspring sired 
154 by extra-group males. The mean length of these periods was $5.4 \pm 5.1$ days (range $=1-22$ 155 days, $\mathrm{N}=28$ ).

156 We summarized our data as offspring-male pairs, each corresponding to one male

157 observed in or near the group during the conceptive period of the mother of each 158 offspring. We included offspring-male pairs only if the male was individually identified

159 and genotyped because we were unable to predict siring success for males who we could 160 not readily identify or for whom we lacked genetic data. Individually-identified and 161 genotyped males comprised most of the males observed in the groups during conceptive 162 periods (mean $\pm \mathrm{sd}=83 \pm 18 \%$, range $=44-100 \%, \mathrm{~N}=28$ offspring). Our data sets did not 163 include the resident of the group in which the offspring was conceived because we

164 focused on competition among extra-group males. The average number of males present 165 in a group per month varied by group and time of year, with peaks typically occurring 166 during mating seasons (Figure 1; Cords 2000). The mean \pm SD number of extra-group

167 males present per conceptive period was $2.5 \pm 2.4$, which included $2.2 \pm 2.1$ bachelor males.

168 Factors Determining Siring Success of Extra-Group Males

169 Our first predictor, male presence, was the proportion of days in the mother's 170 conceptive period in which we observed the male in or on the edge of her group. Our 171 second predictor was male dominance rank. Although male blue monkeys do not 172 regularly live in groups together, they do interact agonistically, thus establishing 173 dominance relationships that may order them into a queue for reproduction (Alberts,

174 Watts \& Altmann 2003). We assigned ranks using the Elo-rating method (Albers \& de 175 Vries 2001; Neumann et al. 2011) implemented with the EloRating package in R (version 176 0.98.1102). In this method, each individual is assigned an initial Elo-rating, which is 
177 recalculated after each dyadic contest, with the winner gaining and the loser losing

178 points. The number of points gained or lost is based on the expected probability of each

179 participant winning the interaction. For example, if a higher-ranking male wins a contest

180 against a lower-ranking male, his Elo-rating increases (and the lower-ranking male's Elo-

181 rating decreases) only slightly. If, however, a lower-ranking male wins an interaction

182 against a higher-ranking male, each male gains or loses more points. This method is

183 particularly appropriate for our study system because it accommodates a varying number

184 and identity of individuals over time, and allows an assessment of rank at any specific

185 timepoint (Neumann et al. 2011). Additionally, the Elo-method can use interactions

186 between all males (including residents) to assign ratings, so bachelors can be ranked

187 relative to each other even if they have not directly interacted.

188 We compiled the 2002-2011 records of dyadic agonistic behavior (chase, attack,

189 lunge, bite, hit, avoid, flee, nasal scream) in which there was a clear winner and loser. All

190 males had a starting rank of 1000 and interacted for 6 months before we assessed their

191 Elo-rating for our data analyses. For our analyses, we used a male's Elo-rating on the day

192 representing the midpoint of the conceptive period for each offspring.

193 Statistical Analysis

194 We used conditional logistic regression (in Stata 13.1) stratified by infant to

195 evaluate how male presence and rank affected the log odds of siring an offspring. We

196 assessed the significance of entire models and individual predictors using likelihood ratio

197 tests to compare models with the predictor(s) present versus absent. Conditional logistic

198 regression requires variation in the dependent variable within each stratum, so for each

199 offspring sired by an extra-group male, we had to observe both the sire and at least one 
200 non-sire (also an extra-group male) at conception. We therefore excluded any offspring

201 for which we observed only one extra-group male at conception. Our first analysis

202 included both neighboring residents and bachelors (both as sires and non-sires). We also

203 assessed how rank and male presence affected the relative success of bachelor males only

204 by generating a second data set that included only bachelor males (both as sires and non205 sires).

206 PART I RESULTS

207 Of the 104 offspring with verified paternity assignments, 68 were assigned to 208 residents. The remaining 36 were assigned to extra-group males, 12 to residents of 209 adjacent groups and 24 to bachelors.

210 Factors Determining Siring Success of Extra-Group Males

211 When we considered offspring sired by any extra-group male, a conditional

212 logistic model including both male presence and rank was better than a null model at 213 predicting which male sired an offspring (likelihood ratio test: $\chi^{2}=13.81, \mathrm{P}=0.001, \mathrm{~N}=11$

214 offspring with one sire and 1-7 non-sires each). However, the effect of male presence was

215 not significant (Wald $\mathrm{P}=0.943$ for rank model), and likelihood ratio tests showed that a

216 model including this predictor did not differ from one that excluded it (rank: $\chi^{2}=0.01$,

$217 \mathrm{P}=0.9433)$. We concluded that male presence was not a useful predictor of siring 218 probability among extra-group males, while rank had significant effects. A final 219 univariate model showed that an extra-group male increased his odds of siring an 220 offspring by a factor of 1.01 with a one-step increase in Elo rating (odds ratio=1.007,

221 Wald $\mathrm{P}=0.008$; likelihood ratio test, $\chi^{2}=13.809, \mathrm{P}=0.0002$ ). The average number of Elo222 steps between two adjacently ranked males was 154 , so the odds of siring an offspring 
223 would increase by a factor of approximately 156 for a one-step increase in ordinal rank.

224 This large rank advantage occurred because the highest-ranked male sired eight of the

225 eleven offspring in our data set and in only one case did a male more than 79 Elo-steps

226 below the highest-ranked male sire the offspring. Overall, the average Elo rating of sires

227 was $1181(\mathrm{~N}=11)$, while for non-sires it was $902(\mathrm{~N}=35)$.

228 We analyzed the effect of male rank and male presence on the log odds of siring

229 an offspring for a subset of the above cases in which bachelors were the sires, and here

230 included only other bachelors as non-sires ( $\mathrm{N}=6$ offspring, with one sire and 1-4 non-

231 sires each). For bachelors competing amongst themselves, neither male presence (Wald

$232 \mathrm{P}=0.645$ ) nor rank (Wald $\mathrm{P}=0.180$ ) predicted siring an offspring, and a model including

233 these predictors was not significantly different from a null model (likelihood ratio test, $\left.234 \quad \chi^{2}=3.031, \mathrm{P}=0.220\right)$.

235 Because conditional logistic regression requires both positive and negative 236 outcomes (sires and non-sires for each offspring), our analyses could not use data from (i)

2377 infants who were known not to be the offspring of their group's resident male, even 238 though they were not assigned to any other male that was present in their group at 239 conception, or (ii) 3 infants whose paternity was assigned to the single extra-group male 240 that visited the group at the time of their conception. These cases can provide information 241 about both non-sires and sires, but one cannot stratify the comparison by offspring. When 242 we considered both neighboring residents and bachelors as sires and non-sires for all 21 243 offspring, we again found that sires had significantly higher Elo-ratings (median for sire: 2441222 vs. non-sires: 912; Mann Whitney $\mathrm{U}$ Test, $\mathrm{U}=649.5, \mathrm{Z}=-3.77$, 2-tailed $\mathrm{P}=0.0002$, $245 \mathrm{~N}=14$ sires, 56 non-sires) but there was no difference for male presence ( $\mathrm{U}=357.5$, 
$246 \mathrm{Z}=0.50, \mathrm{P}=0.6171)$. When we considered only those offspring sired by bachelors $(\mathrm{N}=8)$,

247 we found no significant difference in rank or male presence between bachelor sires and

248 non-sires (rank: $\mathrm{U}=68, \mathrm{P}>0.05$; time in group: $\mathrm{U}=63, \mathrm{P}>0.05, \mathrm{~N}=8$ sires, 14 non-sires for

249 both tests). Thus these results incorporating additional offspring corroborated those from

250 the conditional logistic regression.

251 Part II: Comparing Resident ANd BaChelor SucCess

252 PART II METHODS

253 Comparing Resident and Bachelor Tactics

254 Comparing the long-term success of resident and bachelor tactics required 255 estimating reproduction across multiple groups and years. While our paternity data 256 spanned multiple groups and years, some parameters were not directly measured and 257 were inferred based on known patterns of reproduction in study groups. As such, our 258 calculations were exploratory and served to determine if there are any conditions under 259 which bachelorhood and residency may be comparably successful reproductive tactics.

260 Our calculations were based on MacLeod et al. (2002) who aimed to discover if, 261 over an entire reproductive lifetime, a bachelor samango monkey could steal enough 262 matings to be as successful as a resident male siring at the average rate for one average 263 period of tenure. These authors concluded that a bachelor would have to pursue the steal 264 strategy for 15.1 years to obtain the same number of matings as a resident in one average 265 period of tenure. They judged 15 years to exceed the length of the male reproductive 266 lifespan and concluded that a resident male with just one period of tenure would always 267 obtain more matings than a bachelor. Importantly for our purposes, however, this 268 calculation made four assumptions: (1) the resident confines his reproduction to his 
269 group, (2) the resident loses reproduction to only one bachelor, (3) the bachelor confines

270 his reproduction to one group and (4) that matings map directly onto reproduction. Our

271 paternity results indicated that our study population violated all four assumptions, so we

272 developed a new calculation for comparing bachelor and resident siring success to

273 account for siring success in multiple groups and by multiple bachelors within one group.

274 Specifically, we identified components of bachelor and resident reproduction and used

275 summary statistics to determine how long the average bachelor would have to pursue the

276 bachelor tactic to match the siring success of the average resident.

277 As acknowledged earlier, blue monkey males may switch among tactics during

278 their lives, so some males may sire offspring as bachelors before or after attaining

279 residency. Genetic and behavioral evidence suggest, however, that a resident's siring

280 success is concentrated during residency. In the study population, males who became

281 residents appeared to gain this status around the time they attained full adult body size.

282 As we almost never observed young adult males (i.e., those that are not full grown)

283 copulating, the window in which males that become residents are old enough to copulate

284 but not yet resident in a group is very short, thereby limiting pre-residency siring success.

285 Supporting this inference, only 1 of 8 males sired offspring in a study group before 286 attaining residency and all these offspring were in the group with an infertile resident. We 287 know less about post-residency siring success because many deposed residents (e.g. 7 of 28818 during the study period) disappear. However, demographic records indicate that 5 of 289 the $11(45 \%)$ residents with known fate died and genetic data indicate the other six did 290 not sire offspring as a post-resident bachelor. We therefore computed a resident's siring 291 success based only on his period of residency. 
293 two periods of residency (in different groups). We therefore computed a resident's siring

294 success based on one or two periods of residency.

\section{Resident parameters}

296 Resident siring success during his tenure is expressed as follows (Equation 1):

$$
R=\sum_{t=1}^{T}\left(R_{i}+R_{o} N_{r}\right)_{t}
$$

$297 R_{i}$ is the annual siring rate (number of offspring) in the resident's own group, $R_{0}$ is his

298 annual siring rate per outside group, $\mathrm{N}_{\mathrm{r}}$ is the number of outside groups, and $\mathrm{T}$ is tenure

299 length, measured as the number of mating seasons (one per year in blue monkeys). The

300 product of $R_{o}$ and $N_{r}$ equals "outside-group" siring success, so the value in parentheses is

301 equal to the resident's total annual siring success, which is summed over his entire tenure.

302 We estimated within-group siring success $\left(\mathrm{R}_{\mathrm{i}}\right)$ by summing the number of

303 offspring sired in a resident's group during his entire tenure and dividing by the number

304 of years he was resident. One resident, Ro, did not sire any of the 19 offspring conceived

305 in his group despite mating during most conceptive windows, which suggests that he was

306 infertile. We therefore calculated summary statistics for siring success excluding Ro.

307 There are likely more reproductive opportunities in larger groups, so we

308 calculated $R_{i}$ for small and large groups separately. Small groups contained $\leq 15$ females

309 over age 5 (the age at which females begin to exhibit proceptive behavior) and large

310 groups contained $>15$ females over age 5. Group fissions during the study period resulted

311 in two study group residents ( $\mathrm{Sa}$ and $\mathrm{Pu}$ ) being represented twice, once as resident of the

312 parent group and once as resident of one of the daughter groups. 
Tenure length $(\mathrm{T})$ equaled the number of mating seasons a resident male was in

314 his group, using observations of 23 residents for which we observed complete periods of

315 tenure since 1994. Most conceptions occur during the 5-month mating season from June-

316 October (Cords \& Chowdhury 2010) and we considered a resident to be present for a

317 mating season if he was in the group for more than half of this 5-month period.

318 We estimated the number of outside groups in which a resident may sire offspring

$319\left(\mathrm{~N}_{\mathrm{r}}\right)$ as the number of adjacent groups, because a resident has never been observed more

320 than one home range away from his own group. Group members collaborate to defend

321 territories against adjacent groups (Cords 2007) and we used observations of intergroup

322 encounters from 2002-2012 to assess the number of adjacent groups for each study group.

323 Group fissions and home range shifts may cause the number of adjacent groups to change

324 over time, so we assessed this number annually. In a few cases, the identity of an adjacent

325 group was ambiguous because it was a non-study group without readily identifiable

326 individuals in an area where multiple group home ranges overlapped. In those cases, we

327 calculated the minimum and maximum number of adjacent groups and used the average

328 of those values. Minimum values reflected the number of identified adjacent groups and

329 maximum values included the unidentified adjacent groups, although it may have been a

330 known group that was unrecognized at the time.

331 We estimated outside-group siring success $\left(R_{0}\right)$ from resident paternity success in

332 other study groups. We calculated this parameter for 20 residents with a total of 22

333 periods of residency by dividing the total number of offspring sired in adjacent study

334 groups by the number of adjacent study groups and by tenure length.

\section{Bachelor parameters}




$$
B=\sum_{l=1}^{L}\left(R_{b} N_{b}\right)_{l}
$$

$337 R_{b}$ is the annual siring rate per group, $N_{b}$ is the number of groups encountered, and L is a

338 bachelor's reproductive lifespan. The value in parentheses equals the number of offspring

339 a bachelor produces annually, which is summed over his entire lifetime.

340 We genotyped 47 males who were bachelors for part or all of the time they were

341 observed in the study population and used long-term records to identify the years of

342 bachelorhood and study groups each male visited. To calculate annual siring rate per

343 study group $\left(\mathrm{R}_{\mathrm{b}}\right)$, we divided the total number of offspring a bachelor sired in the study

344 groups by the total number of study groups and years that he was observed.

345 We later omitted some of these males from the calculations to ensure that the

346 summary statistics were good estimates of bachelor parameters. First, we omitted 19

347 bachelors observed for only 1 year, as most were either subadults who had recently

348 emigrated from their natal groups but had not yet left the local population or males that

349 were passing through (i.e., seen only few times and could not be consistently identified).

350 We omitted 3 bachelors who were not observed in any of the study groups because we

351 were unable to assess their siring success. These 22 bachelors were particularly unlikely

352 to sire offspring in the study groups (only one sired one offspring) and removing them

353 increased bachelor siring rate. Of the remaining 25 bachelors, 10 eventually became

354 residents in the study groups or adjacent non-study groups. To control for differences

355 between "committed" bachelors and bachelors who later became residents, we limited

356 our calculations to the 15 bachelors who were bachelors for the entire time we knew 
357 them, although we acknowledge that they may have been residents before or after they 358 were observed.

359 We estimated the number of groups a bachelor encountered as the number of 360 group home ranges that his home range overlapped. From June-September 2011, SJR

361 walked transects following pre-existing linear footpaths spanning the study group home 362 ranges. When she encountered a bachelor, she followed him and recorded his location 363 every 30 minutes with a handheld GPS unit (Garmin GPSMAP ${ }^{\circledR} 60$ CSx) until she lost 364 him. We have location data for 11 bachelor males, but used data from the 5 that were 365 tracked for $\geq 15$ hours each ( $m e a n \pm \mathrm{sd}=24.3 \pm 9.4$, range $=16-38$ hours over 5-11 days).

366 During the same period, we collected location data to map the home ranges of the 3676 study groups. The field team contacted each group daily and recorded the location of 368 the group center every 60 minutes with a handheld GPS unit. We recorded $414 \pm 167$ 369 (mean \pm sd) hours of location data per study group (range=139-579) distributed over 81-

370123 days. SJR and one field assistant also tracked the location of 4 adjacent non-study 371 groups, recording the location of the group center every 30 minutes for a mean of $74 \pm 30$ 372 hours of location data per group (range=37-110) distributed over 14-19 days. We plotted 373 all points on a 50x50m grid. When a point fell within a grid cell, that cell was considered 374 to be part of the group home range (Figure 2).

375 We overlaid bachelor points on group home ranges and counted the number of 376 group home ranges in which each bachelor was observed (i.e., the minimum number of 377 groups encountered). Four of the 5 bachelors were observed outside the mapped group 378 home ranges. Based on home range sizes of known groups and opportunistic observation 379 of unidentified groups, we estimated the total number of group home ranges that 
380 bachelors may have overlapped (i.e., the maximum number of groups encountered). We

381 used the midpoint of minimum and maximum values for each bachelor as the total

382 number of groups encountered.

\section{Comparing tactics}

384 We used mean values for each parameter to calculate the number of years a 385 bachelor siring offspring at the average rate in the average number of groups (i.e., the 386 average bachelor) would have to pursue the bachelor tactic to sire as many offspring as a 387 resident siring at the average rate in his own group and at the average rate in the average 388 number of outside groups (i.e., the average resident) for one period of tenure. The way 389 we calculated all variables accounted for variation across years, so we set Equations 1 390 and 2 equal to each other and solved for the length of a bachelor's reproductive lifespan, 391 L (Equation 3):

$$
L=\frac{T\left(R_{i}+R_{o} N_{r}\right)}{R_{b} N_{b}}
$$

The length of male reproductive lifespans varies widely among cercopithecines

393 (4.3 years in Japanese macaques to 12.7 years in mandrills, Clutton-Brock \& Isvaran 394 2007). We do not know the length of male reproductive lifespans in blue monkeys, so we 395 used estimates of female lifespan to identify plausible values. The oldest female in the 396 study population was 33.5 years old (Cords \& Chowdhury 2010) and males attain full 397 body size around 9 years old, so we estimated the maximum male reproductive lifespan 398 to be the difference between these two values, 24.5 years. We considered it to be 399 impossible for a bachelor to sire as many offspring as a resident if Equation 3 yielded an 400 estimate of $L$ that exceeded 24.5 years. 
Given the large range in tenure length in our population (1-8 years) and the

402 importance of tenure in the above equation, we repeated the calculations using the same

403 parameters but replacing average tenure length with minimum or maximum tenure

404 length. We also doubled all values of $\mathrm{L}$ to compare the average bachelor to the average

405 resident with 2 periods of tenure. These repetitions allowed us to compare bachelor and

406 resident success in a total of 12 unique circumstances.

407 PART II RESULTS

408 Resident parameters

409 The mean annual siring success in a resident's own group was $1.4 \pm 0.9$ offspring

410 per year in small groups ( $\mathrm{N}=5$ residents in 4 study groups) and $2.9 \pm 1.7$ offspring per year

411 in large groups ( $\mathrm{N}=6$ residents in 4 study groups; Table 2). Four residents sired offspring

412 in adjacent groups: 3 residents sired 1 offspring and 1 sired 9 offspring over his 8-year

413 tenure. Despite high outside-group siring success by some males, the average rate across

414 residents was low (mean $\pm \mathrm{sd}=0.1 \pm 0.3$ offspring per adjacent group per year, $\mathrm{N}=22$ periods

415 of residency; Table 1). The number of adjacent groups varied across group-years, but

416 given low rates of outside-group siring success, reproduction in adjacent groups

417 contributed much less to the total number of offspring sired during resident tenure than

418 within-group siring success.

419 Tenure length varied greatly across residents (mean $\pm \mathrm{sd}=2.8 \pm 2.1$, range $=1-8$

420 mating seasons, $\mathrm{N}=23$ periods of residency; Table 1), with observed values skewed

421 towards shorter tenure lengths. Three males maintained residency for 6 years each, but

422 only 1 was resident for the maximum 8 years. 
424 and the number of outside groups into Equation 1 indicated that the average resident in a

425 small group produces 1.4 offspring in his own group and 0.4 offspring in adjacent groups

426 each year, for a total of 1.8 offspring annually. Maintaining this rate would yield 5.0

427 offspring during a period of tenure of average length and 14.7 offspring during a period

428 of tenure of maximum length (Figure 3). In contrast, the average resident in a large group

429 produces 3.3 offspring annually, 9.2 offspring during a period of tenure of average

430 length, and 26.8 offspring during a period of tenure of maximum length (Figure 3). Many

431 of the 10 residents in our study (excluding Ro, who seemed to be infertile; Roberts,

432 Nikitopoulos \& Cords 2014) matched the siring profile of the hypothetical "average

433 resident," siring approximately as many offspring as predicted by the calculations (Figure $4343)$.

\section{Bachelor parameters}

436 An average bachelor sired 0.1 offspring per study group per year (Table 2). We 437 found little variation in the number of group home ranges that a bachelor used 438 (mean $\pm \mathrm{sd}=3.2 \pm 0.4$, range $=2.5-3.5$ groups, Table 2 ). Using mean values for $\mathrm{R}_{\mathrm{b}}$ and $\mathrm{N}_{\mathrm{b}}$, the

439 average bachelor would sire 0.3 offspring per year. There was some variation in siring 440 success among 15 bachelors present in our study population for multiple years (Figure 4).

441 While some had no offspring in our study groups, others sired multiple offspring and

442 several matched the siring profile of the hypothetical "average bachelor," predicted by 443 the calculations (Figure 4).

444 Bachelorhood versus residency 
446 offspring as the average resident who is present for one period of tenure of minimum

447 length in either a small or large group (Table 3). It will always take less time for the

448 average bachelor to match the siring success of a resident in a small group than a resident

449 in a large group, so there are more circumstances that allow the average bachelor to sire

450 as many offspring as the average resident in a small group. For example, the average

451 bachelor may catch up to the average resident who is present for one period of tenure of

452 average length if that resident is in a small group, but not if he is in a large group. The

453 average bachelor would never be able to sire as many offspring as a resident if that

454 resident remains in his group for the maximum tenure length, regardless of group size

455 (Table 3).

456 Doubling all values of $L$ indicates that there are fewer circumstances in which the

457 average bachelor can catch up with the average resident with two periods of residency.

458 Specifically, a bachelor may be as successful as a resident with two periods of residency

459 only if both periods of tenure are short (Table 3 ). If the average resident has one period of

460 tenure in a small group that lasts the minimum tenure length and a second period of

461 tenure in another small group that lasts that mean length, a bachelor may match the

462 resident's siring success in 21.9 years, which is less than our estimate of the maximum

463 male reproductive lifespan.

464 DiscUSSION

465 Factors Affecting Extra-Group Male Siring Success

466 The relationship between rank and male mating and siring success has been a 467 topic of investigation for decades (e.g., Cowlishaw \& Dunbar 1991; Ellis 1995; Majolo et 
468 al. 2012). Studies have focused on species living in multi-male groups where males

469 interact regularly and competitors are in close proximity. To our knowledge, our study is

470 the first to rank extra-group males and use those ranks to predict siring success in a one-

471 male species. Although the resident male of a group dominates within-group reproduction

472 in blue monkeys (Roberts, Nikitopoulos \& Cords 2014), other males also participate, and

473 do so differentially. Our results suggest that higher-ranking extra-group males have a

474 substantial siring advantage; the odds of siring an infant by increased roughly by a factor

475 of 156 with a one-step increase in ordinal rank. High-ranking males include the residents

476 of neighboring groups, which were represented disproportionately among the extra-group

477 sires. Neighboring residents were present during the conceptive period of nine infants and

478 sired six of these infants.

479 Among bachelors, rank was not a significant predictor of siring success, which

480 suggests that bachelors do not engage in contests with other bachelors for access to

481 reproductive opportunities. Indeed, the majority of observed male-male contests involve

482 at least one resident (pers. obs.). Bachelor blue monkeys probably use a highly

483 opportunistic tactic to reproduce, mating when they encounter a sexually active female

484 rather than queuing for reproduction as seen in wild savannah baboons (Alberts, Watts \&

485 Altmann 2003). Opportunistic matings may be more likely to occur in forest-dwelling

486 taxa than in those inhabiting open habitats, because limited visibility decreases the

487 chance that a higher-ranking competitor would interfere (Rowell 1988). We have seen

488 bachelors copulate with females in our study population near to but on the other side of

489 vine tangles from a resident, suggesting that limited visibility does allow bachelors to

490 steal copulations. The dense forest habitat may similarly negate any effect of dominance 
491 rank on siring success among bachelors, allowing low-ranking bachelors to mate and

492 reproduce opportunistically, despite the presence of other higher-ranking bachelors

493 nearby.

494 It is perhaps more surprising that the time an extra-group male visited the group

495 during a mother's conceptive period did not significantly predict siring success. Even in

496 the absence of contests, one might expect extra-group males that are more consistently

497 present to sire more offspring. Perhaps, however, rare opportunities to mate with

498 conceptive females (copulations and mounts during conceptive periods occurred at a rate

499 of 0.21 events/hour; unpublished data from 86 hours of focal samples of 48 adult females

500 in their conceptive period) combined with the difficulty of monitoring their sexual

501 activity in large and widely dispersed groups (group spread: mean $\pm \mathrm{sd}=81 \pm 46 \mathrm{~m}$,

502 range $=15-282 \mathrm{~m}$, unpublished data from 198 measurements of 6 groups with 8-49

503 individuals) in a visually opaque environment introduces a large element of serendipity

504 into relative mating (and ultimately reproductive) success of bachelor males.

\section{Comparing Male Reproductive Tactics}

506 If bachelor male blue monkeys are pursuing an alternative reproductive tactic

507 instead of simply making the best of a bad job, we would expect the lifetime reproductive

508 success of a lifelong bachelor to resemble that of a male who incorporated a period of

509 residency into his reproductive lifespan. Although resident males have a verified

510 reproductive advantage in the short term and on a small scale (Roberts et al. 2014), a

511 bachelor may be able to make up for this reproductive disadvantage by reproducing for a

512 longer period or in more groups (MacLeod, Ross \& Lawes 2002). Our calculations,

513 however, indicate that it will usually take many years for a bachelor to sire as many 
514 offspring as a resident during one period of tenure, and in most circumstances, the

515 resident tactic probably results in higher lifetime reproductive success than the bachelor 516 tactic.

517 Although residency usually confers a reproductive advantage, we identified some 518 circumstances in which an average bachelor's reproductive success would match an 519 average resident with one or two periods of tenure. Specifically, an average bachelor

520 would take 5.8 years to match the siring success of an average resident in a small group 521 with a period of tenure of minimum length. This estimate increases to 10.4 years when 522 one compares an average bachelor to an average resident with minimal tenure in a large 523 group and to 16.1 years in comparison to the average resident in a small group with 524 period of tenure of average length. There were fewer circumstances in which the average 525 bachelor could sire as many offspring as the average resident with two periods of tenure, 526 but it was not impossible.

527 When calculating resident and bachelor parameters, we made several decisions 528 that affected the comparison. We limited resident siring success to the period of residency 529 because the available genetic and behavioral evidence suggests that resident males rarely 530 sire offspring before or after becoming resident. Our data indicate that reproduction by 531 males with at least one period of residency occurred almost entirely during their 532 residency, but it remains possible that this restriction caused us to underestimate resident 533 lifetime reproductive success. Specifically, if residents do sire offspring before and after 534 residency and they both sire offspring at the same rate and live as long as life-long 535 bachelors, the lifetime reproductive success of a resident will always be greater than the 536 lifetime reproductive success of a bachelor. 
537 When calculating annual siring success for bachelors, we eliminated young 538 bachelors who had recently left their natal groups and temporary visitors that were unable 539 to be recognized. These bachelors had very low siring success, so omitting them from our 540 calculation increased the average bachelor siring success and gave the average bachelor a 541 better chance of catching up with a resident. If we included these males, the rate of 542 bachelor siring success was half of the estimated values ( 0.05 offspring per group per 543 year instead of 0.1 offspring per group per year), which would double the number of 544 years required for the average bachelor to sire as many offspring as a resident. The 545 average bachelor would be unable to catch up with the average resident with one period 546 of tenure unless the resident had a very short tenure. The average bachelor would be able

547 to catch up with the resident with two periods of tenure only if the resident had two very 548 short periods of tenure in a small group.

549 We judged the estimates of bachelor reproductive lifespan to be plausible if they 550 were less than 24.5 years, based on the difference between maximum female lifespan and 551 the age at which males attain full adult body size. This male reproductive lifespan 552 represents a maximum, as it is unlikely that male blue monkeys live as long as females. 553 In long-lived species that live in one-male or multi-male groups, males typically show 554 higher annual mortality rates and a more rapid decline in survival with age (Clutton555 Brock \& Isvaran 2007; Bronikowski et al. 2011). If we estimated male reproductive 556 lifespan more conservatively by assuming that the oldest reproductive male was as old as 557 the oldest reproductive female (26.5 years), the male reproductive lifespan would be 17.5 558 years instead of 24.5. This change means there would be fewer circumstances in which a 
559 bachelor male could sire as many offspring as a resident during one period of tenure, but 560 there would still be some (Table 3).

561 Conclusion

562 Although resident male blue monkeys sire most offspring born in their groups, 563 they lose about $40 \%$ of paternity to outside males (Roberts et al. 2014). When a resident

564 male did not monopolize reproduction in his group, the rank of extra-group males

565 influenced their relative success, with high-ranking males (who were often neighboring 566 residents) having a special advantage. Neither bachelor rank nor male presence affected 567 siring success relative to other bachelors, however, suggesting that bachelors do not use 568 contest competition to allocate reproductive opportunities and that opportunistic matings 569 play an important role in bachelor siring success.

570 Bachelor males sire offspring at a much lower rate than do residents, but a 571 bachelor may be able to make up for this reproductive disadvantage by reproducing for a 572 longer period of time or in multiple groups. Our comparison of average bachelor and 573 resident siring success indicated that in most circumstances, a lifelong bachelor would be 574 unlikely to sire as many offspring during his lifetime as a resident during one or two 575 periods of residency. However, a bachelor who sires offspring at the average rate in 576 multiple groups for several years may have similar lifetime reproductive success as a 577 male whose reproduction is limited to one average period of residency, especially in a 578 small group. Our findings thus suggest that one should not assume a resident reproductive 579 advantage for males in one-male groups in all circumstances.

580 ACKNOWLEDGEMENTS

581 We thank the Government of Kenya for permission to conduct the research, and 
582 the Centre for Kakamega Tropical Forest Studies at Masinde Muliro University of 583 Science and Technology for local sponsorship. Genetic resources utilized in this study 584 were provided by the government and people of Kenya. We are grateful to the local forest

585 station personnel, and many field and lab assistants. We especially thank T. Disotell for 586 hosting the genetic analysis and D. Rabinowitz for statistical advice. 


\section{REFERENCES}

588 Albers PCH, de Vries H. 2001. Elo-rating as a tool in the sequential estimation of 589 dominance strength. Animal Behaviour. 61: 489-495.

590 Alberts SC, Watts HE, Altmann J. 2003. Queuing and queue-jumping: long-term

591 patterns of reproductive skew in male savannah baboons, Papio cynocephalus.

592 Animal Behaviour. 65: 821-840.

593 Asa CS. 1999. Male reproductive success in free-ranging feral horses. Behavioral $594 \quad$ Ecology \& Sociobiology. 47: 89-93.

595 Bronikowski AM, Altmann J, Brockman DK, Cords M, Fedigan LM, Pusey AE, Stoinski 596 T, Morris WF, Strier KB, Alberts SC. 2011. Aging in the natural world:

597 comparative data reveal similar mortality patterns across primates. Science. 331:

$598 \quad 1325-1328$.

599 Clutton-Brock TH. 1982. The functions of antlers. Behaviour. 79: 108-125.

600 Clutton-Brock TH, Isvaran K. 2007. Sex differences in ageing in natural populations 601 of vertebrates. Proceedings of the Royal Society B: Biological Sciences. 274: $3097-$ 6023104.

603 Cords M. 2000. The number of males in guenon groups. In: Kappeler P, editors.

604 Primate Males. New York: Cambridge University Press. p. 84-96.

605 Cords M. 2002. When are there influxes in blue monkey groups? In: Glenn ME, Cords 606 M, editors. The Guenons: Diversity and Adaptation in African Monkeys. New York: $607 \quad$ Kluwer Academic Publishers. p. 189-201.

608 Cords M. 2007. Variable participation in the defense of communal feeding territories 609 by blue monkeys in the Kakamega Forest, Kenya. Behaviour. 144: 1537-1550. 
610 Cords M. 2012. The 30-year blues: what we know and don't know about life history,

611 group size and group fission of blue monkeys in the Kakamega Forest, Kenya. In:

612 Kappeler PM, Watts DP, editors. Long-term Field Studies of Primates. Berlin:

613 Springer. p. 289-312.

614 Cords M, Chowdhury S. 2010. Life history of Cercopithecus mitis stuhlmanni in the

615 Kakamega Forest, Kenya. International Journal of Primatology. 31: 433-455.

616 Cowlishaw G, Dunbar RIM. 1991. Dominance rank and mating success in male

617 primates. Animal Behaviour. 41: 1045-1056.

618 Ellis L. 1995. Dominance and reproductive success among nonhuman animals: a

619 cross-species comparison. Ethology and Sociobiology. 16: 257-333.

620 Fabiani A, Galimberi F, Sanvito S, Hoelzel RA. 2004. Extreme polygyny among

621 southern elephant seals on Sea Lion Island, Falkland Islands. Behavioral Ecology.

$622 \quad 15: 961-969$.

623 Feh C, Munkhtuya B. 2008. Male infanticide and paternity analyses in a socially

624 natural herd of Przewalski's horses: sexual selection? Behavioural Processes. 78:

$625 \quad 335-339$.

626 Gross MR. 1996. Alternative reproductive strategies and tactics: diversity within

627 sexes. Trends in Ecology \& Evolution. 11: 92-98.

628 Heckel G, Von Helversen 0. 2003. Genetic mating system and the significance of

629 harem associations in the bat Saccopteryx bilineata. Molecular Ecology. 12: 219-

$630 \quad 227$. 
631 Hirsch BT, Maldonado JE. 2011. Familiarity breeds progeny: sociality increases 632 reproductive success in adult male ring-tailed coatis (Nasua nasua). Molecular 633 Ecology. 20: 409-419.

634 Hoelzel AR, Le Boeuf BJ, Reiter J, Campagna C. 1999. Alpha-male paternity in 635 elephant seals. Behavioral Ecology \& Sociobiology. 46: 298-306.

636 Kalinowski ST, Taper ML, Marshall TC. 2007. Revising how the computer program 637 Cervus accommodates genotyping error increases success in paternity 638 assignment. Molecular Ecology. 16: 1099-1106.

639 Launhardt K, Borries C, Hardt C, Epplen JT, Winkler P. 2001. Paternity analysis of 640 alternative male reproductive routes among the langurs (Semnopithecus 641 entellus) of Ramnagar. Animal Behaviour. 61: 53-64.

642 Le Boeuf BJ. 1974. Male-male competition and reproductive success in elephant 643 seals. American Zoologist. 14: 163-176.

644 MacLeod MC, Ross C, Lawes MJ. 2002. Costs and benefits of alternative mating 645 strategies in samango monkey males. In: Glenn ME, Cords M, editors. The 646 Guenons: Diversity and Adaptation in African Monkeys. New York: Kluwer 647 Academic Publishers. p. 203-216.

648 Majolo B, Lehmann J, de Bortoli Vizioli A, Schino G. 2012. Fitness-related benefits of 649 dominance in primates. American Journal of Physical Anthropology. 147: 652650660.

651 Mitchell N, Schaab G, Wagele JW. 2009. Kakamega Forest ecosystem: An 652 introduction to the natural history and the human context. BIOTA East Africa 653 Report No. 5, Karlruher Geowissenschaftlicher Schriften A. 17: 1-58. 
654 Mugatha S, Ogutu J, Cords M, Maitima J. 2007. Dynamics of male residence and

655 female oestrus during a breeding season of blue monkeys in the Kakamega

656 Forest, Kenya. African Journal of Ecology. 45: 49-54.

657 Neff BD, Svensson EI. 2013. Polyandry and alternative mating tactics. Philosophical

658 Transactions of the Royal Society B: Biological Sciences. 368: 20120045.

659 Neumann C, Duboscq J, Dubuc C, Ginting A, Irwan AM, Agil M, Widdig A, Engelhardt

660 A. 2011. Assessing Dominance Hierarchies: validation and advantages of

661 progressive evaluation with Elo-rating. Animal Behaviour. 82: 911-921.

662 Pazol K, Carlson AA, Ziegler TE. 2002. Female reproductive endocrinology in wild

663 blue monkeys: a preliminary assessment and discussion of potential adaptive

664 functions. In: Glenn ME, Cords M, editors. The Guenons: Diversity and Adaptation

665 in African Monkeys. New York: Kluwer Academic Publishers. p. 217-232.

666 Pemberton JM, Albon SD, Guinness FE, Clutton-Brock TH, Dover GA. 1992.

667 Behavioral estimates of male mating success tested by DNA fingerprinting in a

668 polygynous mammal. Behavioral Ecology. 3: 66-75.

669 Pope T. 1990. The reproductive consequences of male cooperation in the red howler

670 monkey: paternity exclusion in multi-male and single-male troops using genetic

671 markers. Behavioral Ecology \& Sociobiology. 27: 439-446.

672 Repka J, Gross MR. 1995. The evolutionarily stable strategy under individual

673 condition and tactic frequency. Journal of Theoretical Biology. 176: 27-31.

674 Roberts SJ, Nikitopoulos E, Cords M. 2014. Factors affecting low resident male siring

675 success in one-male groups of blue monkeys. Behavioral Ecology. 25: 852-861.

676 Rowell TE. 1988. Beyond the one-male group. Behaviour. 104: 189-201. 
677 Rowell TE, Chism J. 1986. Sexual dimorphism and mating systems: jumping to 678 conclusions. In: Pickford M, Chiarelli B, editors. Sexual dimorphism in living and 679 fossil primates. Firenze: Il Seicesimo. p. 107-111.

680 Schwartz 0, Armitage K. 1980. Genetic variation in social mammals: the marmot 681 model. Science. 207: 665-667.

682 Sommer V, Rajpurohit L. 1989. Male reproductive success in harem troops of 683 Hanuman langurs (Presbytis entellus). International Journal of Primatology. 10: $684 \quad 293-317$.

685 Storz JF, Bhat H, Kunz T. 2001. Genetic consequences of polygyny and social 686 structure in an Indian fruit bat, Cynopterus sphinx. II. Variance in male mating 687 success and effective population size. Evolution. 55: 1224-1232.

688 Taborsky M, Brockmann HJ. 2010. Alternative reproductive tactics and life history 689 phenotypes. In: Kappeler P, editors. Animal Behavior: Evolution and Mechanisms. 690 Berlin: Springer. p. 537-586.

691 Widemo F. 1998. Alternative reproductive strategies in the ruff, Philomachus 692 pugnax: a mixed ESS? Animal Behaviour. 56: 329-336.

693 Wolff J0. 2008. Alternative reproductive tactics in nonprimate male mammals. In:

694 Oliviera RF, Taborsky M, Brockmann HJ, editors. Alternative Reproductive 695 Tactics: An Integrative Approach. New York: Cambridge University Press. p. 356696372.

697 


\section{1}

Graph of number of males in groups

Average number of males (including the resident male) present in each group averaged by month during the study period. Vertical dashed lines indicate dates of group fission events. Gray columns indicate the population peak in conceptions, which occurs from July until September.
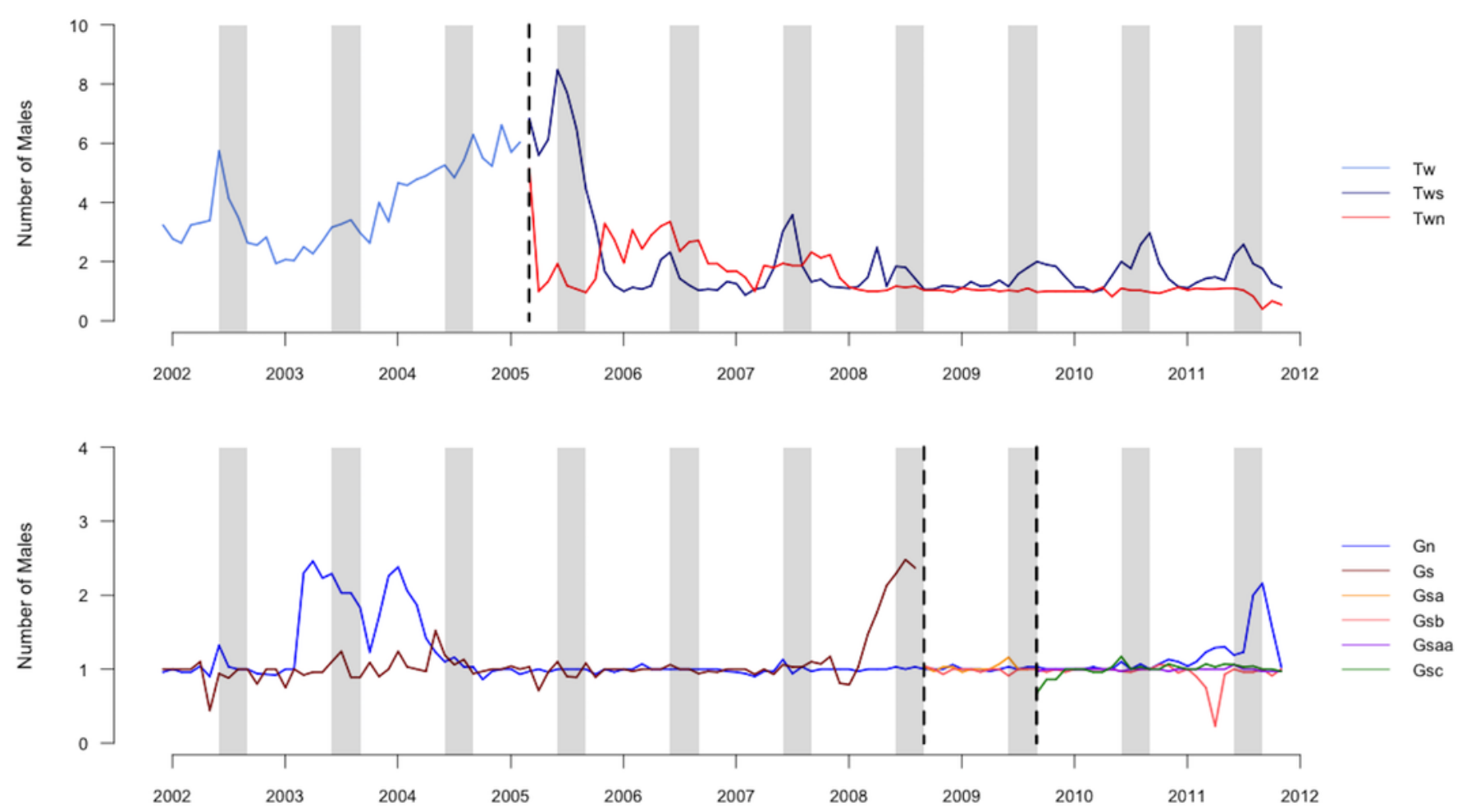
Figure 2 (on next page)

Map of group home ranges

Home ranges of 6 study groups (white) and 4 adjacent non-study groups (hatched). Dark grey indicates forested areas, light grey non-forested areas. 
PeerJ Reviewing Manuscript

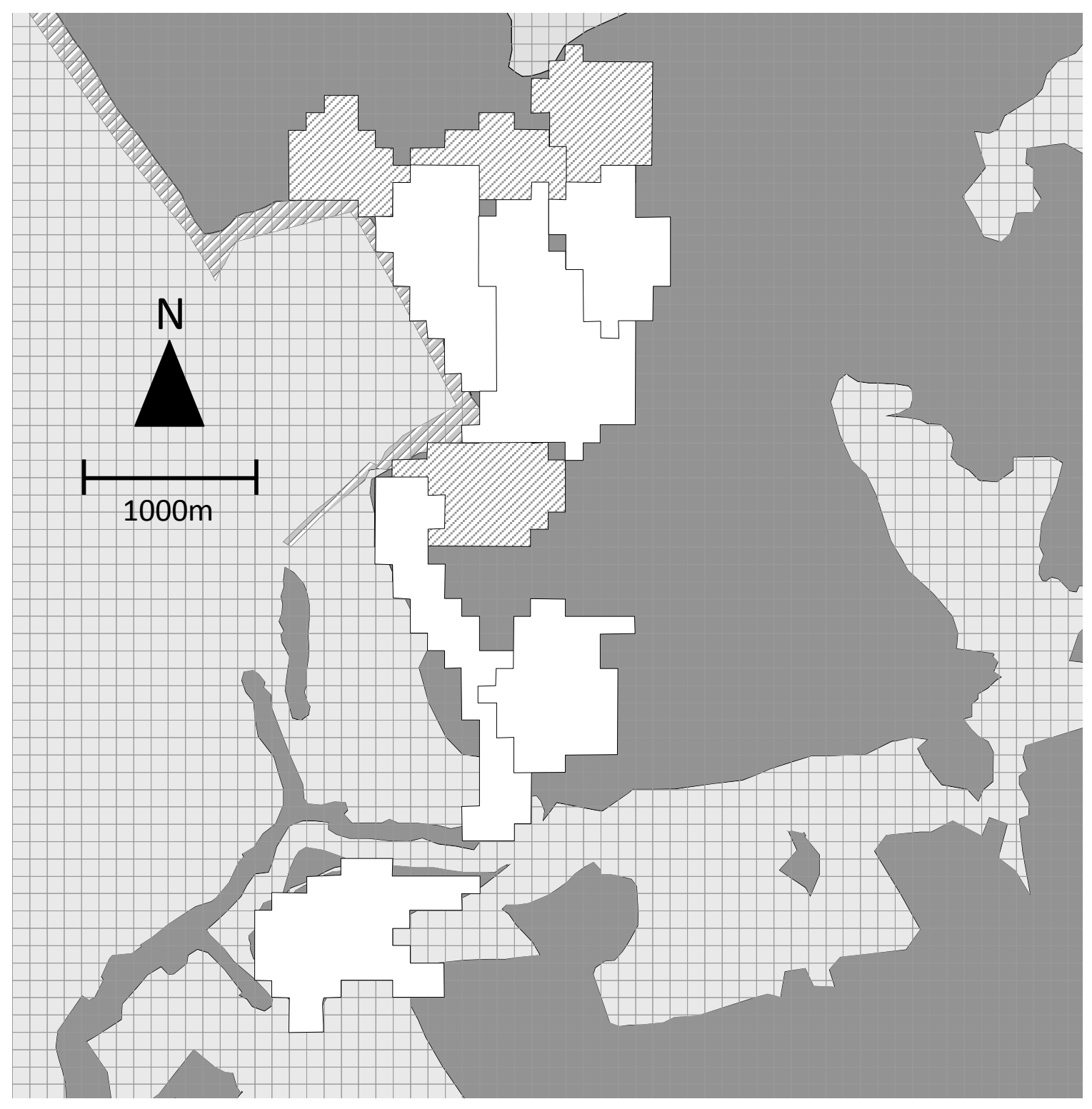


Table $\mathbf{1}$ (on next page)

Resident parameters

Resident parameters 


\begin{tabular}{|c|c|c|c|c|c|}
\hline Statistic & $\begin{array}{l}\text { Annual within- } \\
\text { group siring rate in } \\
\text { small groups }\left(\mathbf{R}_{\mathrm{i}}\right)\end{array}$ & $\begin{array}{l}\text { Annual within- } \\
\text { group siring rate in } \\
\text { large groups }\left(\mathbf{R}_{\mathbf{i}}\right)\end{array}$ & $\begin{array}{l}\text { Annual siring rate } \\
\text { per neighboring } \\
\text { group }\left(R_{0}\right)\end{array}$ & $\begin{array}{c}\text { Number of } \\
\text { neighboring groups } \\
\left(\mathrm{N}_{\mathrm{r}}\right)\end{array}$ & $\begin{array}{c}\text { Tenure length in } \\
\text { years }(T)\end{array}$ \\
\hline Mean \pm SD & $1.4 \pm 0.9$ & $2.9 \pm 1.7$ & $0.1 \pm 0.3$ & $4.4 \pm 1.5$ & $2.8 \pm 2.1$ \\
\hline Median & 1.3 & 3.1 & 0 & 4 & 2 \\
\hline Range & $0.5-3$ & $0-5$ & $0-1$ & $1-7$ & $1-8$ \\
\hline $\mathrm{N}$ & $\begin{array}{c}5 \text { residents in } 4 \text { study } \\
\text { groups }\end{array}$ & $\begin{array}{c}6 \text { residents in } 4 \text { study } \\
\text { groups }\end{array}$ & $\begin{array}{l}20 \text { residents in the } \\
\text { study pop, } 22 \text { periods } \\
\text { of residency }\end{array}$ & 45 group-years & $\begin{array}{l}21 \text { residents in the } \\
\text { study pop, } 23 \text { periods } \\
\text { of residency }\end{array}$ \\
\hline
\end{tabular}




\section{Table 2 (on next page)}

Bachelor parameters

Bachelor parameters 
2 Table 2 Bachelor parameters

\begin{tabular}{lll}
\hline Statistic & $\begin{array}{l}\text { Annual siring rate } \\
\text { per group }\left(\mathbf{R}_{\mathbf{b}}\right)\end{array}$ & $\begin{array}{l}\text { Number of } \\
\text { groups }\left(\mathbf{N}_{\mathbf{b}}\right)\end{array}$ \\
\hline Mean $\pm \mathrm{sd}$ & $0.1 \pm 0.1$ & $3.2 \pm 0.4$ \\
Median & 0 & 3.5 \\
Range & $0-0.3$ & $2.5-3.5$ \\
$\mathrm{~N}$ & 29 bachelors & 5 bachelors \\
\hline
\end{tabular}

3 


\section{Table 3 (on next page)}

Comparison of resident and bachelor success

The number of years $(L)$ an average bachelor would need to pursue the bachelor tactic to sire as many offspring as an average resident with one (A) or two (B) periods of tenure of various lengths. Gray cells correspond to values that exceed a male's maximum reproductive lifespan (24.5 years) and therefore circumstances in which a bachelor could not sire as many offspring in his lifetime as a resident sires during his tenure. 
A. Average Resident with One Period of Tenure

\begin{tabular}{lcccccc} 
& \multicolumn{2}{c}{$\begin{array}{c}\text { Min Tenure } \\
\text { (1 year) }\end{array}$} & \multicolumn{2}{c}{$\begin{array}{c}\text { Mean Tenure } \\
(2.8 \text { years })\end{array}$} & \multicolumn{2}{c}{$\begin{array}{c}\text { Max Tenure } \\
\text { (8 years) }\end{array}$} \\
\hline & $\begin{array}{l}\text { Small } \\
\text { Group }\end{array}$ & $\begin{array}{l}\text { Large } \\
\text { Group }\end{array}$ & $\begin{array}{l}\text { Small } \\
\text { Group }\end{array}$ & $\begin{array}{c}\text { Large } \\
\text { Group }\end{array}$ & $\begin{array}{c}\text { Small } \\
\text { Group }\end{array}$ & $\begin{array}{c}\text { Large } \\
\text { Group }\end{array}$ \\
\hline $\begin{array}{l}\text { L for the } \\
\text { Average } \\
\text { Bachelor }\end{array}$ & 5.8 & 10.4 & 16.1 & 29.3 & 46.0 & 83.5 \\
\hline \hline
\end{tabular}

B. Average Resident with Two Periods of Tenure

Min Tenure

(1 year)

\begin{tabular}{lcccccc}
\hline & $\begin{array}{l}\text { Small } \\
\text { Group }\end{array}$ & $\begin{array}{l}\text { Large } \\
\text { Group }\end{array}$ & $\begin{array}{l}\text { Small } \\
\text { Group }\end{array}$ & $\begin{array}{c}\text { Large } \\
\text { Group }\end{array}$ & $\begin{array}{l}\text { Small } \\
\text { Group }\end{array}$ & $\begin{array}{c}\text { Large } \\
\text { Group }\end{array}$ \\
\hline $\begin{array}{l}\text { L for the } \\
\text { Average } \\
\text { Bachelor }\end{array}$ & 11.6 & 20.8 & 32.2 & 58.6 & 92.0 & 167.0 \\
\hline
\end{tabular}

Max Tenure

Mean Tenure

(8 years) 3 


\section{3}

Resident siring success

Predicted siring success of hypothetical average residents as calculated by substituting mean values for $R_{i}, R_{0}$, and $N_{r}$ into Equation 1. Points correspond to 10 real residents in our study population and indicate the total number of offspring sired in the study groups during one period of tenure. One male was resident in both a large and a small group.

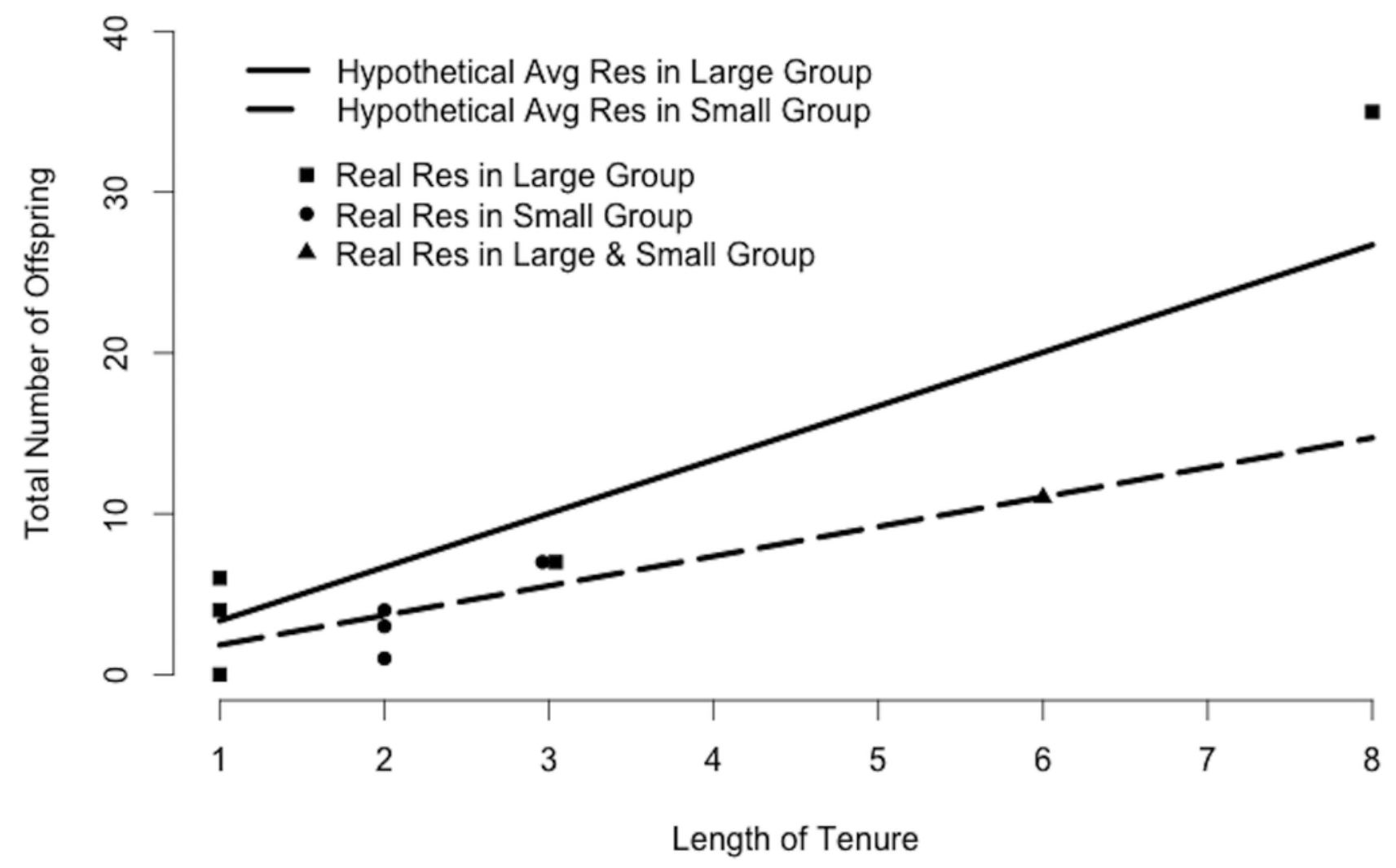


4

Bachelor siring success

Predicted siring success of a hypothetical average bachelor as calculated by substituting mean values for $R_{b}$ and $N_{b}$ into Equation 2. Points correspond to 15 real bachelors and indicate the total number of offspring sired in the study groups during the years the bachelor was observed in our study population.

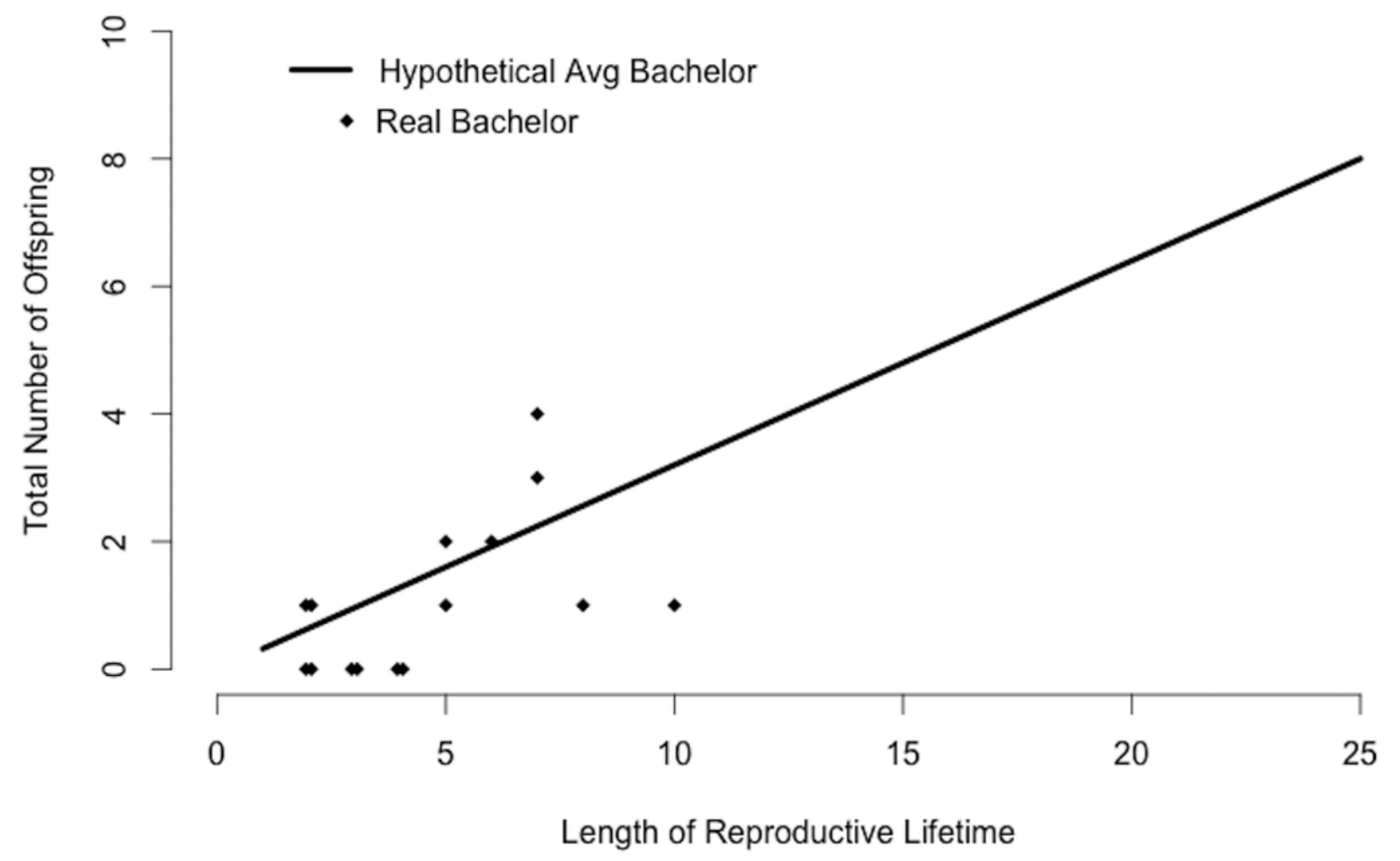

